Article

\title{
Experimental Investigation on the Effects of DBD Plasma on the Film Cooling Effectiveness of a 30-Degree Slot
}

\author{
Ye Jee Kim ${ }^{1}$, Gi Mun Kim ${ }^{1}$, Youhwan Shin ${ }^{2}$ and Jae Su Kwak ${ }^{1, *}$ \\ 1 School of Aerospace and Mechanical Engineering, Korea Aerospace University, Goyang 10417, Korea; \\ yourrt@hanmail.net (Y.J.K.); skydprs@naver.com (G.M.K.) \\ 2 Center for Urban Energy Research, Korea Institute of Science and Technology, Seoul 02792, Korea; \\ yhshin@kist.re.kr \\ * Correspondence: jskwak@kau.ac.kr; Tel.: +82-2-300-0103
}

Academic Editor: Xianchang Li

Received: 22 March 2017; Accepted: 15 June 2017; Published: 19 June 2017

\begin{abstract}
The effects of dielectric barrier discharge (DBD) plasma on the film cooling effectiveness of a 30-degree slot was experimentally investigated in a low-speed wind tunnel. The pressure sensitive paint (PSP) technique was used to measure the film cooling effectiveness, and two blowing ratios (0.5 and 1.0) were tested. A sinusoidal waveform with a 1-kHz frequency was supplied to the exposed electrode. Two input voltages $(6$ and $7 \mathrm{kV}$ ) and two exposed electrode locations were considered. The results showed that the film cooling effectiveness of the slot was higher for the blowing ratio of the 1.0 case than that for the blowing ratio of the 0.5 case regardless of plasma operation. The higher input voltage case $(7 \mathrm{kV})$ showed higher film cooling effectiveness than the lower input voltage case $(6 \mathrm{kV})$. The improvement in film cooling effectiveness facilitated by the DBD plasma was more significant when the coolant had less momentum. The maximum improvement of the area averaged film cooling effectiveness was $2.3 \%$ for the case with the exposed electrode located at the slot exit and a blowing ratio of 0.5 .
\end{abstract}

Keywords: gas turbine; slot film cooling; film cooling effectiveness; pressure sensitive paint (PSP); dielectric barrier discharge (DBD) plasma

\section{Introduction}

Film cooling is commonly applied to the hot section of a gas turbine in order protect the components from hot combustion gas. In film cooling, coolant is injected through discrete holes or slots and forms a thin film above the surface that needs to be cooled [1]. Since the film prevents the hot mainstream from transferring heat directly to the surface, heat transfer can be significantly reduced. The film cooing technique is usually applied to first stage vanes, rotors, and nearby endwalls that operate in high temperature conditions and experience high heat loads [2]. Since the coolant is extracted from a compressor and the amount of coolant is limited, many researchers have tried to improve film cooling effectiveness with the minimal use of coolant [3].

The turbine endwall is one region requiring sophisticated cooling techniques because it experiences high heat loads and thermal stress due to the complex flow phenomena [4]. On the turbine endwall, there are gaps (i.e., slots) between stationary vanes and rotating blades. In order to prevent the inhalation of hot combustion gas through these slots, coolant is injected through them. The injected coolant provides film protection on the endwall of the blade passage and blade leading edge.

Many researchers have experimentally studied the effects of slot purge flow on turbine endwall film cooling in a linear turbine cascade. Papa et al. [5] investigated the distribution of the Sherwood 
number near the endwall slot using the Nepheline sublimation method. They also showed traces of the injected coolant using the oil-dot visualization method. Oke et al. [6] conducted an experimental study on the effects of the momentum ratio on film cooling from a double slot located upstream of the leading edge of a vane. They showed that the distribution of the coolant was strongly affected by the momentum flux ratio. Gao et al. [7] and Wright et al. [8] installed slots simulating the stator-rotor seal of a gas turbine, and they then measured the film cooling effectiveness using the pressure sensitive paint (PSP) technique for different blowing ratios and mainstream turbulence levels. They showed that a high coolant flow rate was required to fully cover the turbine endwall with a single slot, or other discrete holes were required for a smaller coolant flow through the slot.

There have been many attempts to actively control the flow using a dielectric barrier discharge (DBD) plasma actuator. The actuator consists of two electrodes and a dielectric barrier between them. One of the electrodes is exposed to the air and the other one is insulated from the air. Generally, the plasma is formed around the area between the edge of the exposed electrode and the insulated electrode [9]. The mechanism of the DBD plasma-induced airflow is still under discussion [10]. However, many researchers agree that when a sufficiently high amplitude AC to generate electron-ion pairs is supplied to the electrodes, an asymmetric electric field is formed and the gas near the exposed electrode is ionized [11-14]. When the charged particles near the exposed electrode accelerate toward the insulated electrode, the particles collide and transfer momentum to the surrounding gas. As a result, the gas near the electrodes is induced toward the insulated electrode. This flow is called an induced flow [15].

DBD plasma is widely applied in various industries. It is used in ozone generation, pollution control, surface treatments, and flat plasma displays $[16,17]$. In this study, flow control using a DBD plasma-induced flow is utilized in order to increase film cooling effectiveness. Since DBD plasma actuators have particular advantages-i.e., no moving parts, extremely fast response times, low mass, and low input power [11] - many researchers have tried to utilize them to control flow separation or actively control the flow itself. Corke et al. [18] and He et al. [19] applied simple DBD plasma on airfoil surfaces and successfully controlled the flow separation on those surfaces. Huang et al. [20] tried to control the flow separation on the suction side of the low-pressure turbine blade using DBD plasma. Van Ness II et al. [21] and Stephens et al. [22] applied DBD plasma near the tip of a squealer tip blade to reduce the tip leakage flow.

Researchers have also tried to enhance the DBD plasma induced flow. Benard et al. [23] experimentally investigated the effects of the input waveform shape on the DBD plasma actuator. They utilized various multi-frequency waveform types and showed that the velocity profile of the induced flow was strongly affected by the input waveform. Enloe et al. [24] showed that the velocity of the induced flow increased as the width of the insulated electrode increased for the case with triangular waveform input power. Pons et al. [10] experimentally investigated the effects of the magnitude and frequency of the input power, as well as the thickness of the dielectric barrier on the DBD plasma induced flow. Their results showed that the velocity of the induced flow was higher for the case with a higher voltage, higher frequency, and thinner dielectric barrier.

Some researchers have attempted to improve film cooling effectiveness using DBD plasma. Yu et al. [25] numerically studied the effects of the mainstream velocity, blowing ratio, number of actuators, electrode position, and power input on the film cooling effectiveness of a 35-degree cylindrical film cooling hole. Dai et al. [26] also conducted a numerical study on three film cooling hole shapes and showed that the DBD plasma suppressed the counter-rotating vortex pair and improved the film cooling effectiveness. Audier et al. [27] experimentally investigated the effects of DBD plasma on slot film cooling using IR thermography. They showed that the film cooling effectiveness increased by up to $15 \%$ after applying DBD plasma.

Previous studies have shown that DBD plasma can improve film cooling effectiveness by inducing the coolant toward the endwall. Most of these were numerical studies. The aforementioned experimental study [27] utilized IR thermography, the results of which were sensitive to the 
temperature increase caused by the DBD plasma. In this study, DBD plasma was applied to a 30-degree film slot, and the effects of blowing ratio, input voltage, and the location of the electrode on the film cooling effectiveness were experimentally investigated. For the film cooling measurements, the PSP technique was utilized in order to avoid the effects of the temperature increase from the DBD plasma.

\section{Experimental Setup}

Figure 1 presents the schematics of the test setup. The width and height of the wind tunnel duct were $200 \mathrm{~mm}$ and $100 \mathrm{~mm}$, respectively, and the mainstream velocity was $10 \mathrm{~m} / \mathrm{s}$. Pressure sensitive paint (PSP) (UF-750P, Innovative Scientific Solutions, Inc., Dayton, OH, USA) was sprayed on the test surface and an LED lamp with a 400-nm wavelength (LM2xLZ-400, Innovative Scientific Solutions, Inc., Dayton, OH, USA) was installed above the test section for PSP illumination. The light emitted from the PSP was captured using a 14-bit cooled CCD camera (pco. 1600, PCO AG, Kelheim, Germany) with a 650-nm long pass filter and stored on a computer. For the film cooling test, air and nitrogen were used as a coolant, and the resulting coolant density ratio $\left(\mathrm{DR}=\rho_{c} / \rho_{\infty}\right.$, where $\rho_{c}$ and $\rho_{\infty}$ are the density of coolant and mainstream flow, respectively) was about 1.0. The coolant was supplied to the slot through the plenum, and two blowing ratios ( $\mathrm{M}=\rho_{c} u_{c} / \rho_{\infty} u_{\infty}$, where $u$ is streamwise velocity) (0.5 and 1.0) were tested.

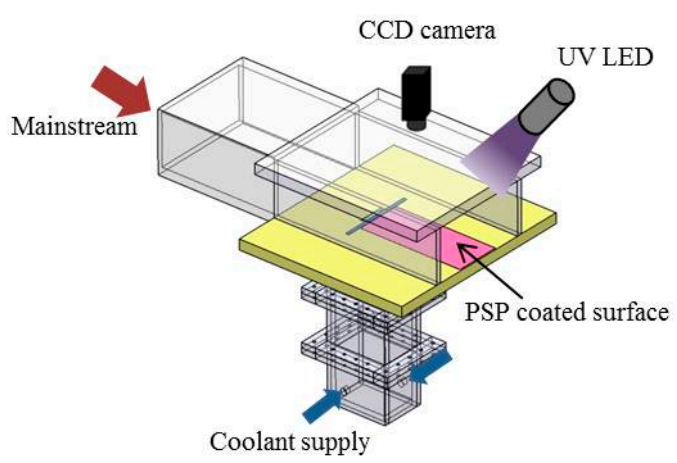

(a) Test setup

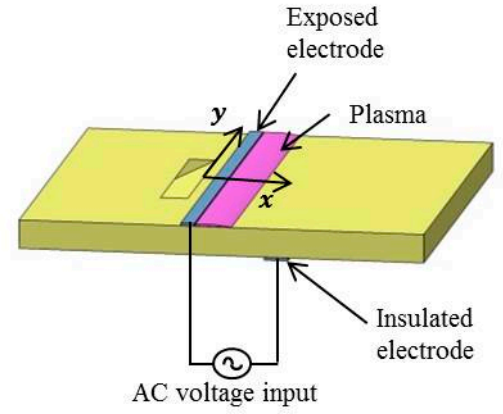

(b) DBD plasma actuator and electrodes

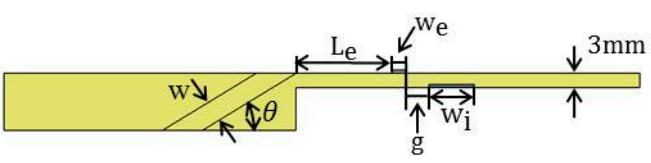

(c) Detailed view of slot and electrode installation locations

Figure 1. Schematic of test setup (not to scale).

Figure $1 \mathrm{~b}, \mathrm{c}$ show the schematic of the slot with the DBD plasma actuator. A function generator (AFG 3021, Tektronix, Inc., Beaverton, OR, USA) and a power amplifier (20/20C, TREK, Inc., Lockport, NY, USA) were used to generate the sinusoidal wave and amplify the signal. A $0.07-\mathrm{mm}$ thick 
aluminum tape was used for both electrodes. The width of the exposed and insulated electrodes were 3 and $10 \mathrm{~mm}$, respectively. The electrodes were attached to a 3-mm thick dielectric barrier plate (Bakelite), and the distance between the two electrodes was $5 \mathrm{~mm}$. The slot had a 30-degree angle with respect to the mainstream flow, and the width $(w)$ and length of the slot $\left(l_{\mathrm{s}}\right)$ were 4 and $12 \mathrm{~mm}$, respectively.

The sinusoidal waveform with a $1-\mathrm{kHz}$ frequency was supplied to the exposed electrode and two amplitudes $(6$ and $7 \mathrm{kV})$ were tested. Figure 2 presents the waveforms of the input voltage and current for the case with the $6 \mathrm{kV}$ input voltage. In order to investigate the effects of electrode location, two distances $\left(L_{e}\right)$ between the slot and the exposed electrode $(0$ and $10 \mathrm{w})$ were considered. The coolant density ratio $(D R)$ was 1.0 , and two blowing ratios $(M)(0.5$ and 1.0$)$ were tested.

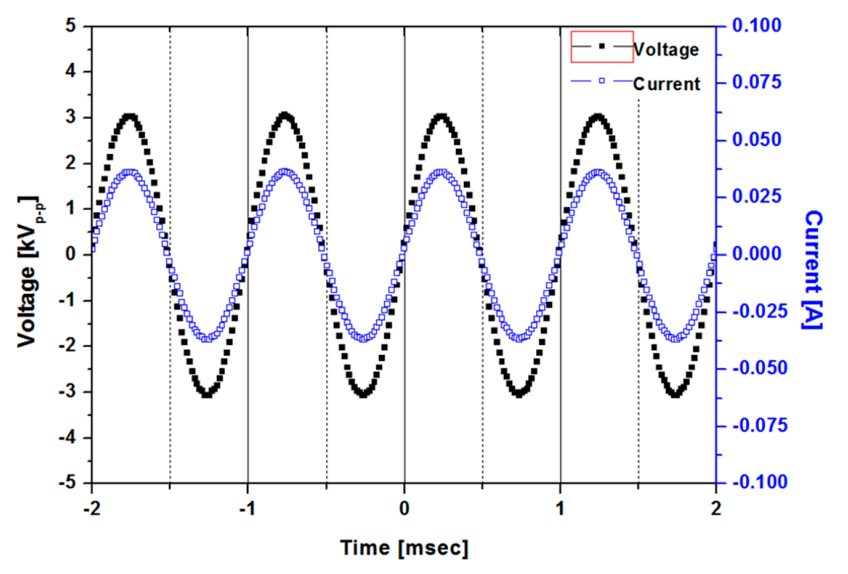

Figure 2. Waveforms of the input voltage and current (6 kV input voltage case).

\section{Pressure-Sensitive Paint Technique}

The PSP technique was used for the film cooling measurements in this study. PSP is a paint with luminescent molecules in an oxygen permeable polymer binder. If the luminescent molecules are illuminated by near-ultraviolet light, they emits light. The intensity of this light depends on the number of oxygen molecules, i.e., the pressure of the PSP coated surface. Due to oxygen quenching [28], the intensity of the emitted light is inversely proportional to the concentration of oxygen. Figure 3 shows the PSP calibration results. The PSP was calibrated with a separate vacuum chamber, and the same CCD camera and LED lamp that were used for the film cooling tests were also utilized for the calibration test. Because the intensity $(I)$ of emitted light is also affected by the surrounding temperature, PSP calibration tests were conducted for different temperature conditions, and an appropriate calibration curve was selected for the film cooling test.

In order to measure the film cooling effectiveness using PSP, two separate tests with different coolants were required. If air or foreign gases (nitrogen for the current study) are injected as a coolant and the intensity of light emitted from the PSP for each coolant case is compared, the film cooling effectiveness $(\eta)$ can be calculated using Equation (1) [7,29]:

$$
\eta=\frac{C_{\text {mix }}-C_{\text {air }}}{C_{\mathrm{fg}}-C_{\text {air }}}=\frac{\left(P_{\mathrm{O}_{2}}\right)_{\text {air }}-\left(P_{\mathrm{O}_{2}}\right)_{\text {mix }}}{\left(P_{\mathrm{O}_{2}}\right)_{\text {air }}}=1-\frac{1}{\left(1+\left(\frac{P_{\mathrm{O}_{2, \text { air }}} / P_{\mathrm{O}_{2, \text { ref }}}}{P_{\mathrm{O}_{2, \mathrm{fg}}} / P_{\mathrm{O}_{2, \text { ref }}}} 1\right) \frac{W_{\mathrm{fg}}}{W_{\text {air }}}\right)}
$$

In Equation (1), $C$ and $P_{\mathrm{O}_{2}}$ are the oxygen concentration and the partial pressure of oxygen, respectively. $\mathrm{W}$ is the molecular weight of the air or coolant. The subscripts air, mix, fg, and ref denote the mainstream, the mainstream-coolant mixture, the foreign gas, and the reference conditions, respectively.

The partial pressure ratios in Equation (1) can be calculated from the PSP calibration results, as shown by Equation (2): 


$$
\frac{\left(P_{\mathrm{O}_{2}}\right)}{\left(P_{\mathrm{O}_{2}}\right)_{\text {ref }}}=\mathrm{f}\left(\frac{I_{\text {ref }}-I_{\mathrm{blk}}}{I-I_{\mathrm{blk}}}\right)
$$

For the film cooling measurements with PSP, four intensity images at difference conditions are required. Table 1 presents the conditions under which each image was acquired.

Table 1. Images required for the pressure sensitive paint (PSP) technique.

\begin{tabular}{ccccc}
\hline Images & Subscript & Light Condition & $\begin{array}{c}\text { Wind Tunnel } \\
\text { Condition }\end{array}$ & Coolant Injection \\
\hline Black image & blk & Off & Off & Off \\
Reference & ref & On & Off & Off \\
image & air & On & On & Air \\
Air image & fg & On & On & Coolant \\
Foreign gas & image & & & \\
\hline
\end{tabular}

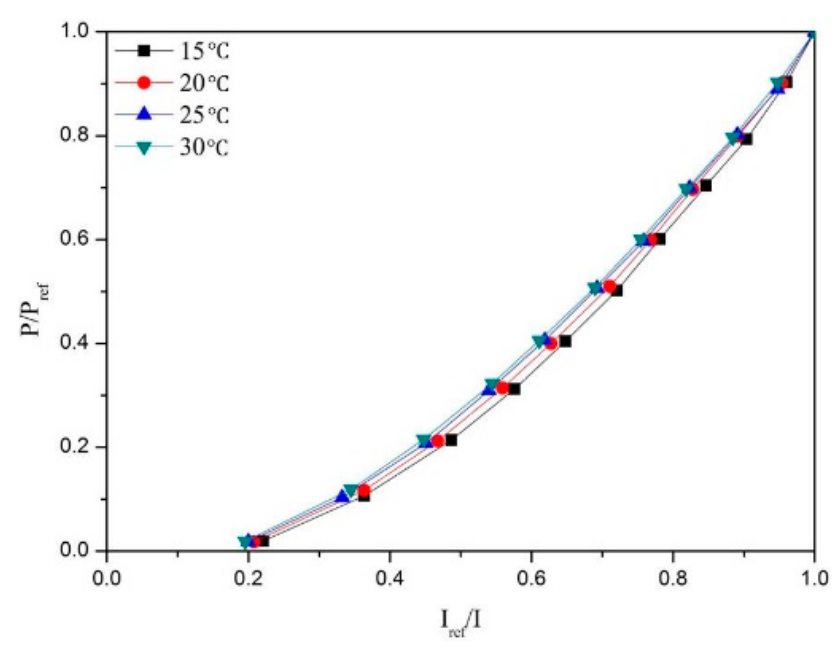

Figure 3. Pressure sensitive paint (PSP) calibration curve.

The experimental uncertainty $[30,31]$ in the measured film cooling effectiveness was estimated using Equation (3). The estimated uncertainties were about $0.78 \%$ and $1.98 \%$ for the film cooling effectiveness values of 0.8 and 0.6 , respectively. For the film cooling effectiveness value of 0.4 , the uncertainty was estimated as $4.28 \%$.

$$
\Delta \eta=\sqrt{\left(\frac{\partial \eta}{\partial I_{\text {air }}} \Delta I_{\text {air }}\right)^{2}+\left(\frac{\partial \eta}{\partial I_{\mathrm{N}_{2}}} \Delta I_{\mathrm{N}_{2}}\right)^{2}+\left(\frac{\partial \eta}{\partial I_{\text {ref }}} \Delta I_{\text {ref }}\right)^{2}+\left(\frac{\partial \eta}{\partial I_{\mathrm{blk}}} \Delta I_{\mathrm{blk}}\right)^{2}}
$$

\section{Results}

Figure 4 shows the distribution of the film cooling effectiveness for the case without plasma with blowing ratios of 0.5 and 1.0. The exposed electrode was installed at the $0 \mathrm{w}$ location. However, power was not supplied to the electrode. Half of the film cooling effectiveness contours for each case were presented together for better comparison. The results showed that very high film cooling effectiveness was observed near the slot exit, and the film cooling effectiveness decreased downstream. Without plasma, the higher blowing ratio case $(M=1.0)$ showed higher film cooling effectiveness at the same location. 
Figure 5 presents the distribution of the film cooling effectiveness with the exposed actuator installed at the $0 \mathrm{w}$ location. The plasma-off cases are also presented for comparison. The film cooling effectiveness was higher for the higher blowing ratio cases regardless of plasma operation, and the distribution of the film cooling effectiveness did not significantly change as a result of the plasma operation for both input voltage cases.

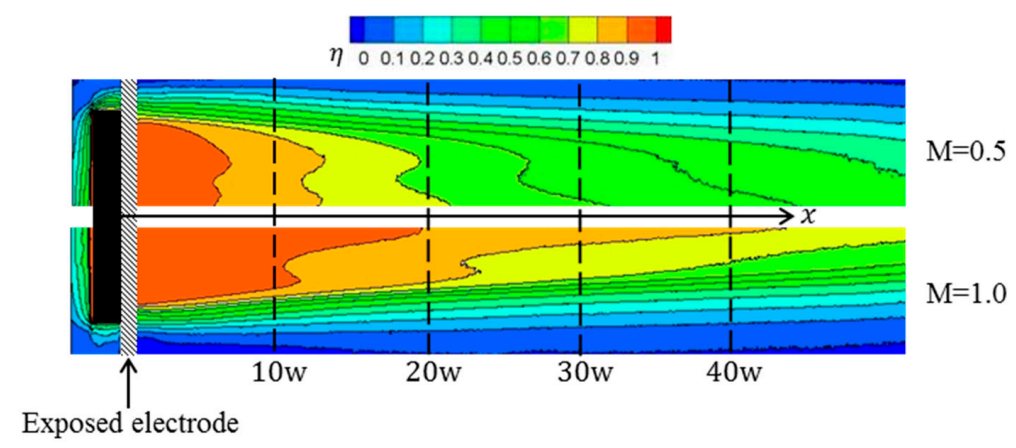

Figure 4. Distribution of film cooling effectiveness without plasma.

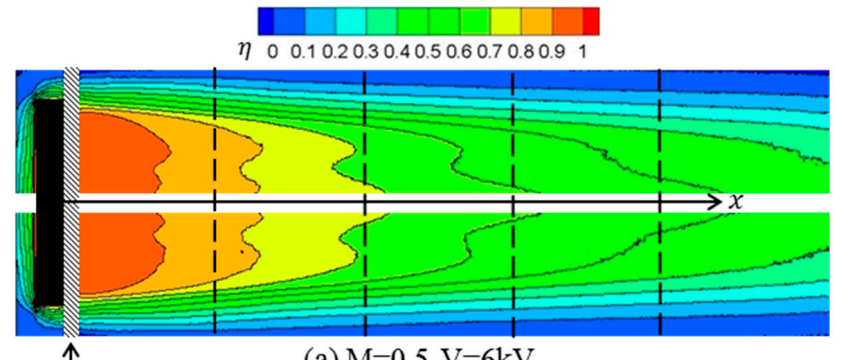

Plasma off

Exposed electrode

(a) $\mathrm{M}=0.5 \mathrm{~V}=6 \mathrm{kV}$

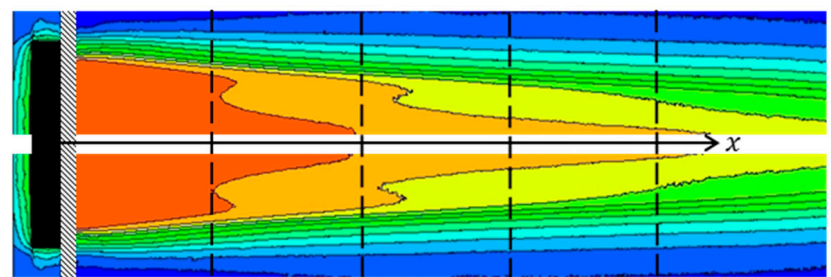

Plasma off

(b) $\mathrm{M}=1.0 \mathrm{~V}=6 \mathrm{kV}$

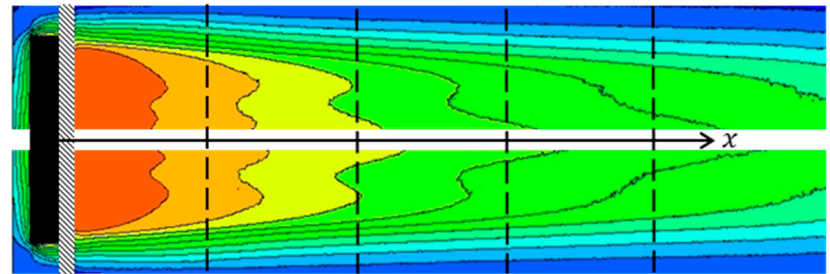

Plasma off

(c) $\mathrm{M}=0.5 \mathrm{~V}=7 \mathrm{kV}$

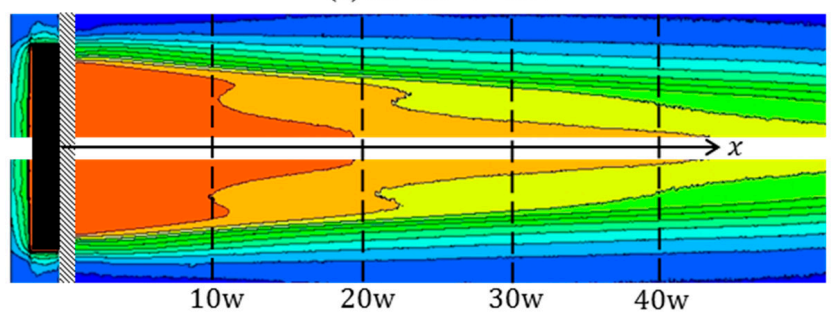

Plasma off

(d) $\mathrm{M}=1.0 \mathrm{~V}=7 \mathrm{kV}$

Figure 5. Distributions of film cooling effectiveness $\left(L_{\mathrm{e}}=0 \mathrm{w}\right)$. 
For a quantitative comparison, the laterally-averaged film cooling effectiveness is presented at Figure 6. The laterally-averaged film cooling effectiveness for each case was not significantly different near the slot. However, the difference between the plasma-off and plasma-on cases increased downstream. Both cases showed higher laterally-averaged film cooling effectiveness, and the higher voltage case performed better. As the coolant was dragged down toward the endwall by the plasma-induced flow, the film cooling effectiveness increased, as shown in Figure 7. Since the strength of the plasma-induced flow was proportional to the input voltage and frequency [32], the higher input voltage resulted in higher film cooling effectiveness. The effect of the plasma on the film cooling effectiveness was more significant for the lower blowing ratio case $(M=0.5$, Figure 5) because the coolant for the lower blowing ratio case had less momentum and could be relatively easily affected by the plasma-induced flow.

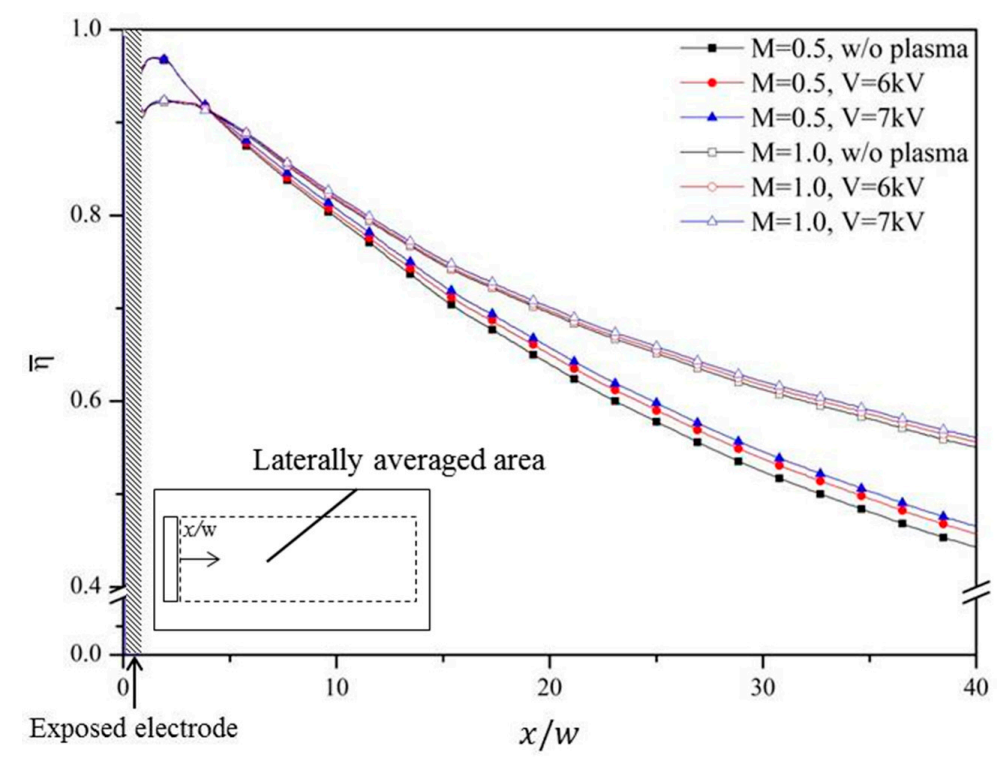

Figure 6. Laterally-averaged film cooling effectiveness $\left(L_{\mathrm{e}}=0 \mathrm{w}\right)$.

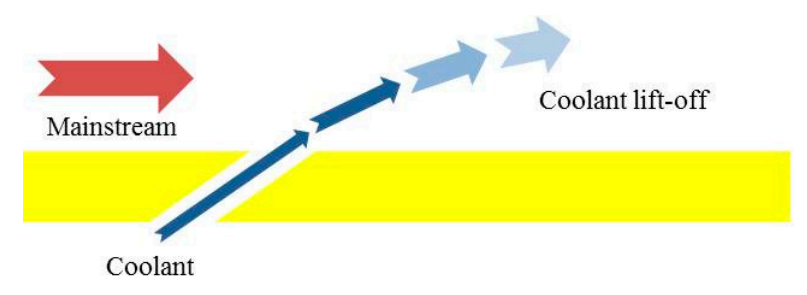

(a) Without plasma condition

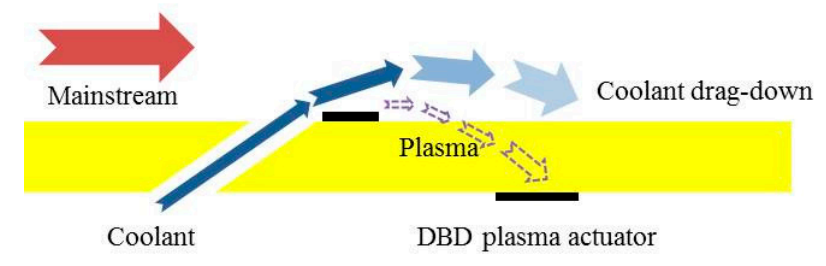

(b) With plasma condition

Figure 7. Schematic of the flow with the dielectric barrier discharge (DBD) plasma. 
Figure 8 presents the distributions of the film cooling effectiveness with the exposed electrode installed at the $10 \mathrm{w}$ location. Again, these distributions were not significantly affected by the plasma operation. However, the laterally averaged film cooling effectiveness in Figure 9 clearly shows the effects of plasma on the film cooling effectiveness. The laterally-averaged film cooling effectiveness between the slot and the exposed electrode was almost identical for the plasma-off and plasma-on cases. However, the effects of plasma and input voltage on the film cooling were clearly observed downstream from the exposed electrode. The plasma-on cases showed higher averaged film cooling effectiveness, and the higher input voltage cases resulted in higher film cooling effectiveness in this region.
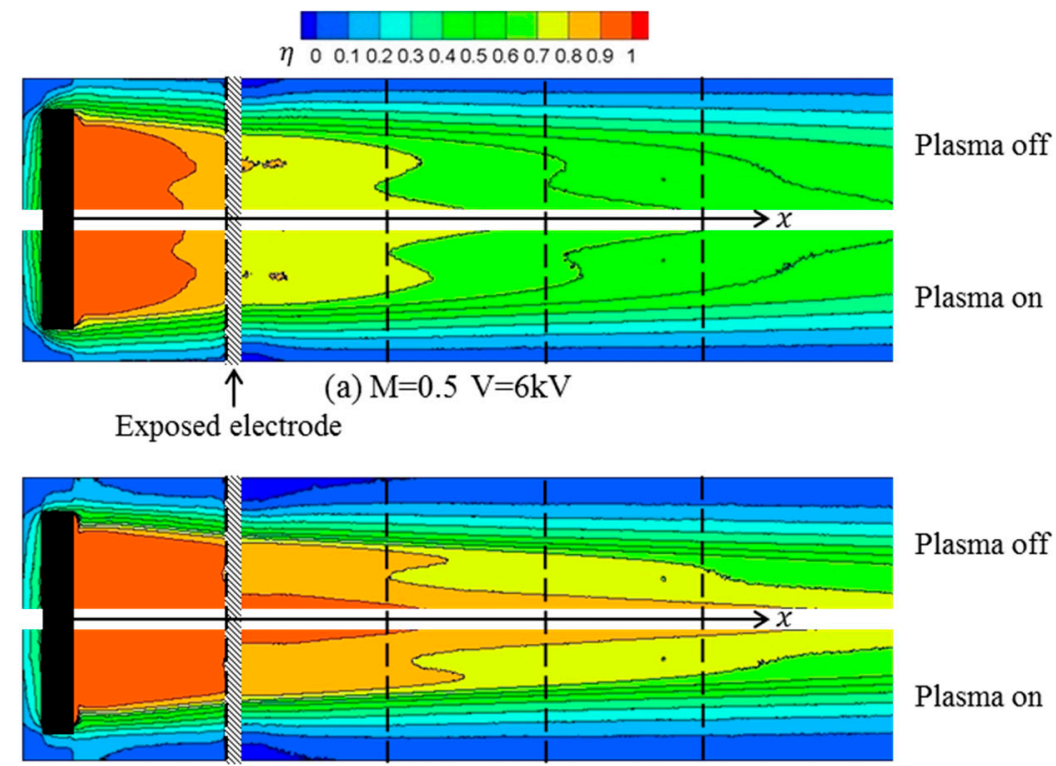

Plasma off

(b) $\mathrm{M}=1.0 \mathrm{~V}=6 \mathrm{kV}$

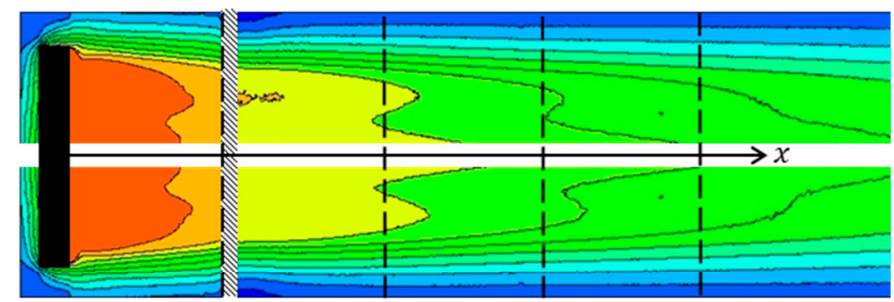

Plasma off

(c) $M=0.5 \quad \mathrm{~V}=7 \mathrm{kV}$
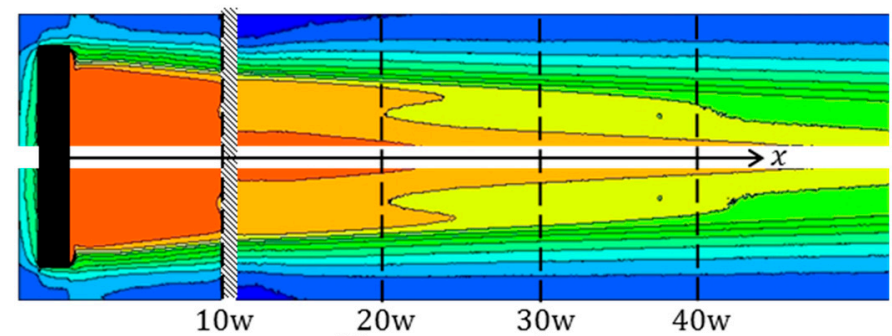

Plasma off

(d) $\mathrm{M}=1.0 \mathrm{~V}=7 \mathrm{kV}$

Figure 8. Distributions of film cooling effectiveness $\left(L_{\mathrm{e}}=10 \mathrm{w}\right)$. 


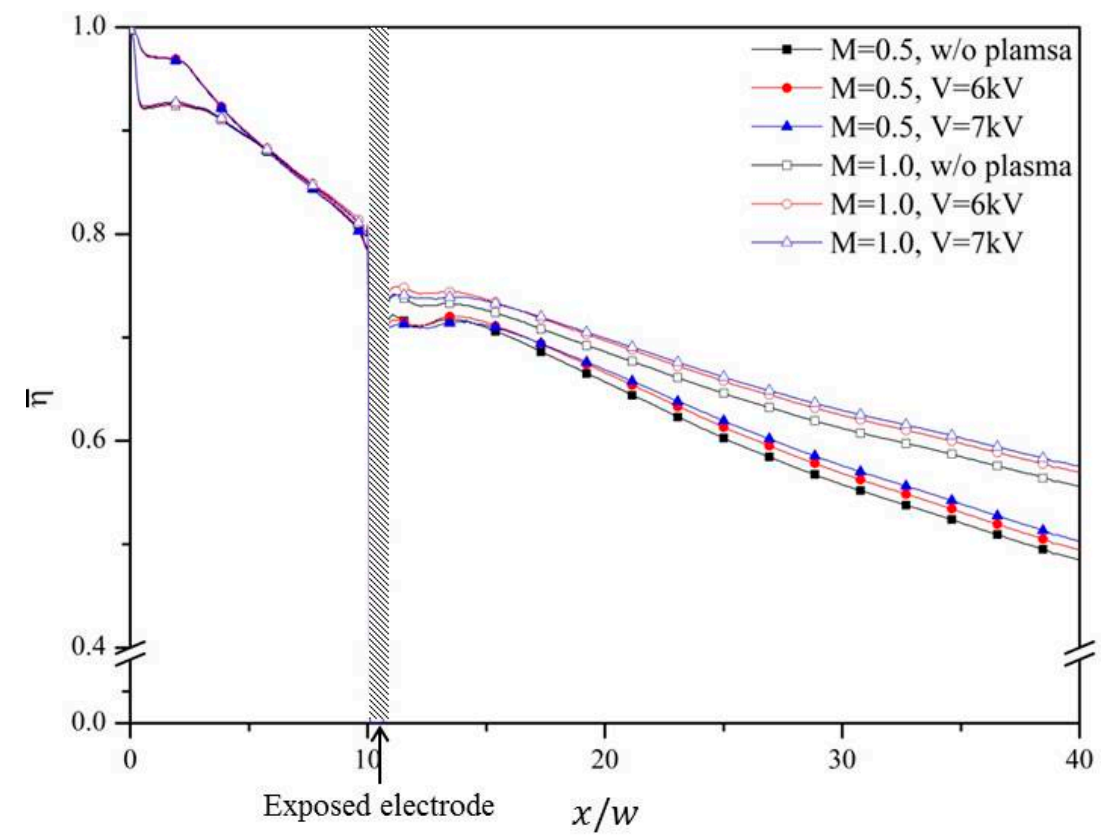

Figure 9. Laterally-averaged film cooling effectiveness $\left(L_{\mathrm{e}}=10 \mathrm{w}\right)$.

An important point is made apparent in Figure 9. Though the improvement of the film cooling due to the plasma only constitutes a few percent and may be within the level of measurement uncertainty, the almost identical laterally-averaged film cooling effectiveness between the slot and the exposed electrode for three different test conditions demonstrates the repeatability of the current test. Therefore, it can be asserted that DBD plasma can improve film cooling effectiveness even though the improvement was not significant in the test cases.

Figure 10 shows the overall area averaged film cooling effectiveness for the tested cases. Regardless of the location of the exposed electrode or the blowing ratio, the higher input voltage case showed a higher averaged film cooling effectiveness. For the case with the exposed electrode at $0 \mathrm{w}$ (Figure 10a,b), the effects of the plasma on film cooling effectiveness were higher for the lower blowing ratio case (Figure 10a) because of the lower coolant momentum. For the higher blowing ratio case (Figure 10b), the plasma-induced flow might not have been strong enough to drag down more coolant toward the endwall. The film cooling effectiveness increased slightly even for the $7 \mathrm{kV}$ input voltage case.

For the cases with the exposed electrode at $10 \mathrm{w}$, the higher blowing ratio case (Figure 10d) presented slightly better improvement in averaged film cooling effectiveness than the case with the exposed electrode at $0 \mathrm{w}$. Since the momentum of the coolant downstream from $x / w=10$ was lower than that near the slot, more coolant could be dragged down by the plasma-induced flow, and this resulted in improved film cooling.

In order to investigate the effect of the ionized gas caused by the DBD plasma on the PSP emitting intensity, a separate test was conducted. Figure 11 shows the setup for the test. The widths of the exposed and the insulated electrodes were 5 and $10 \mathrm{~mm}$, respectively. Both electrodes were made of $0.07-\mathrm{mm}$ thick copper tape and attached on the 3-mm thick acrylic plate. The mainstream velocity was $10 \mathrm{~m} / \mathrm{s}$, and the input voltage was set as $6 \mathrm{kV}$.

Figure 12 presents the spanwise averaged intensity difference for the cases with and without plasma. The results showed that the averaged intensity difference reached its maximum point near the exposed electrode, and it continuously decreased downstream. The maximum difference was about $0.5 \%$. For the film cooling effectiveness of 0.8 , a $0.5 \%$ increase in $I_{\text {air }}$ and $I_{\mathrm{fg}}$ resulted in about a $0.03 \%$ increase in film cooling effectiveness. Therefore, overestimation in the film cooling effectiveness due to the plasma and ionized gas had very little effect on the measured film cooling effectiveness. 


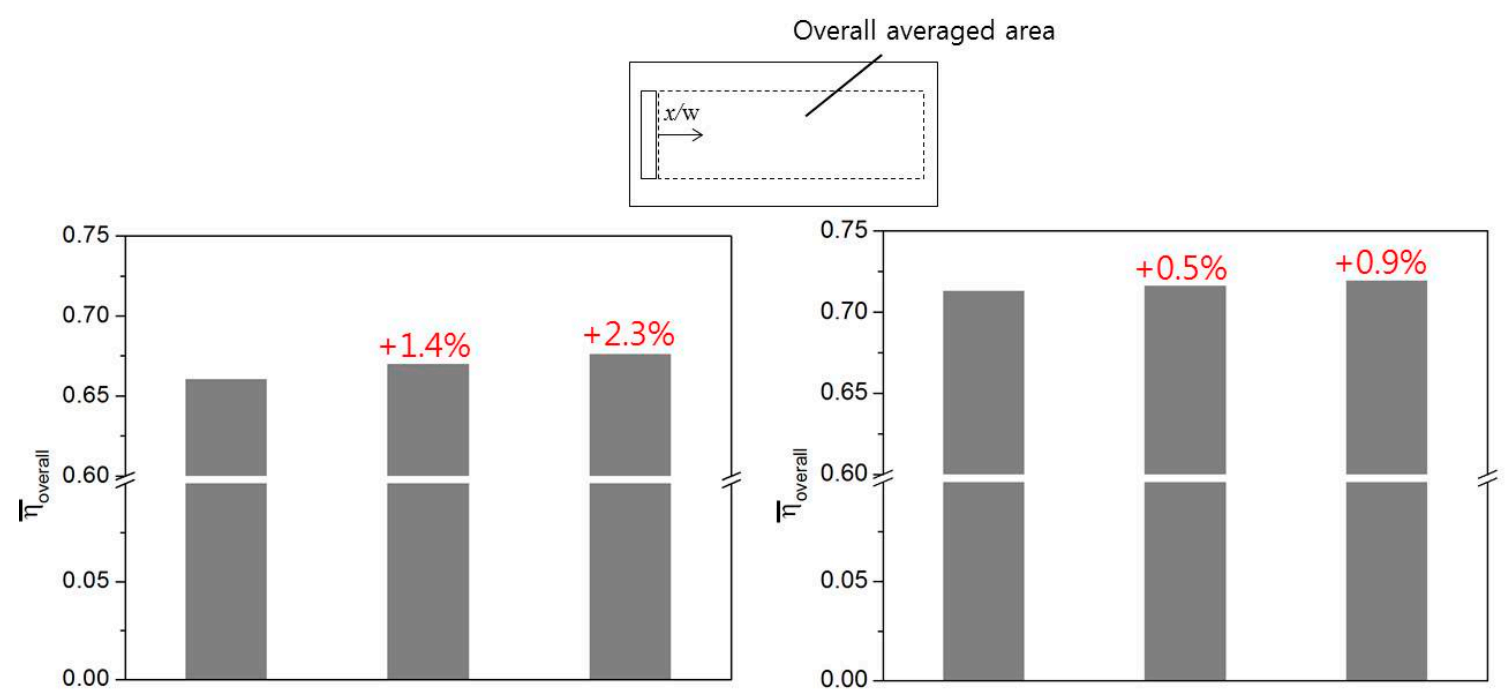

(a) $\mathrm{M}=0.5 \quad L_{e}=0 \mathrm{w}$

(b) $\mathrm{M}=1.0 \quad L_{e}=0 \mathrm{w}$

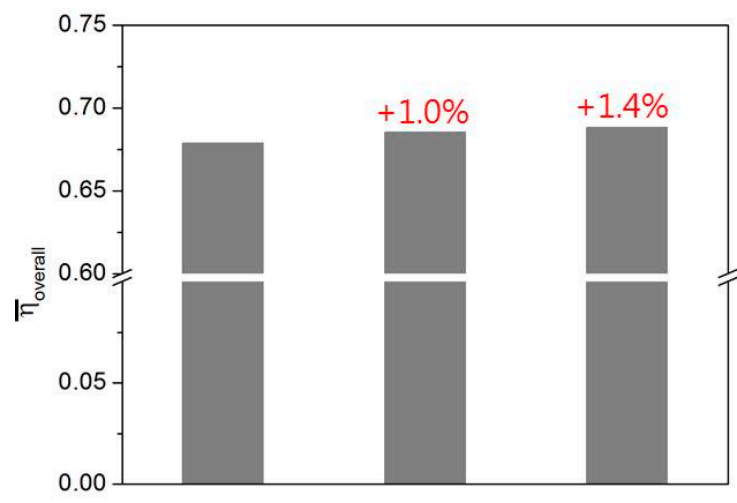

(c) $\mathrm{M}=0.5 L_{e}=10 \mathrm{w}$

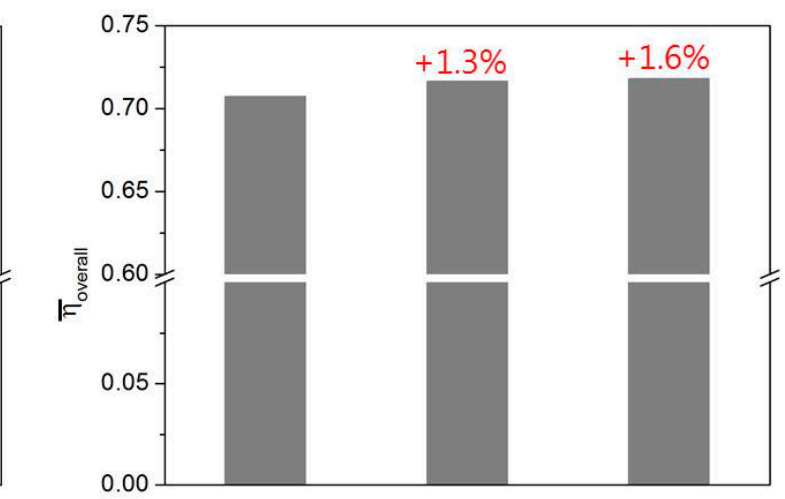

(d) $\mathrm{M}=1.0 \quad L_{e}=10 \mathrm{w}$

Figure 10. Overall area averaged film cooling effectiveness.

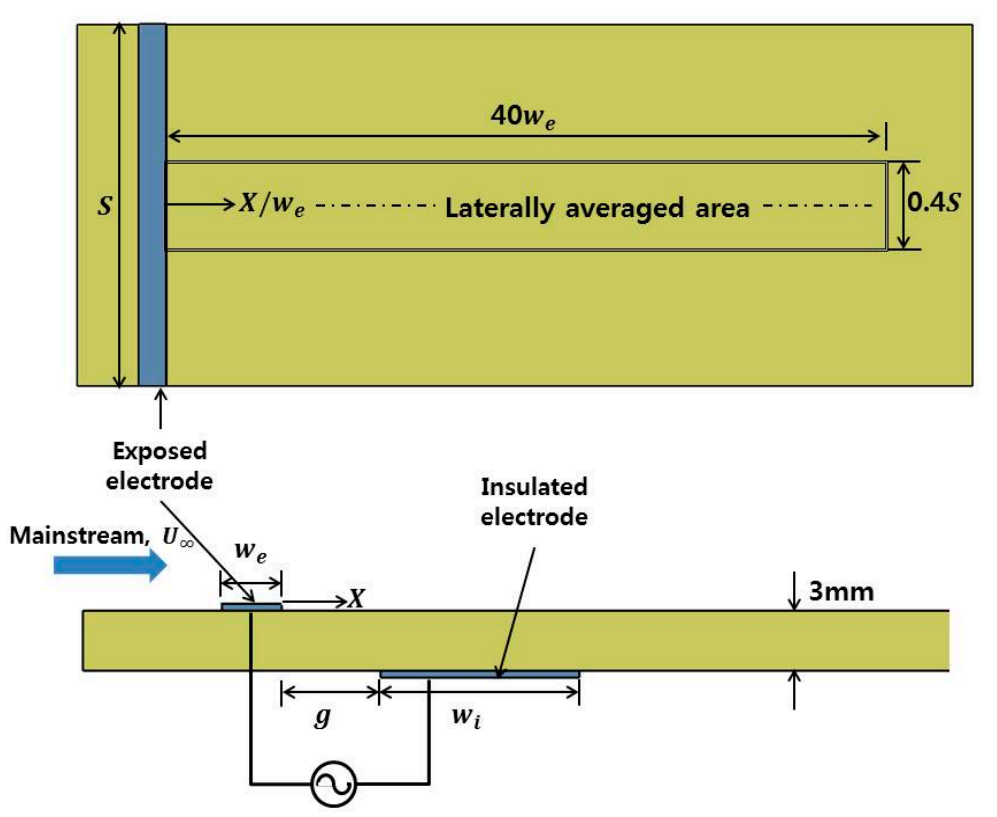

Figure 11. Test setup to investigate the effect of plasma on the PSP emission. 


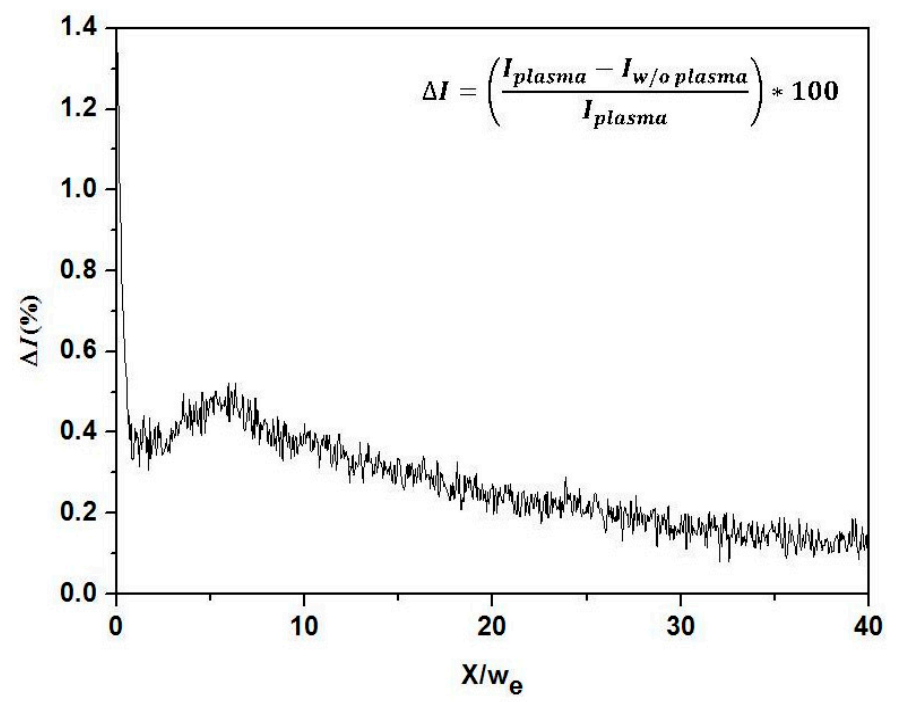

Figure 12. Laterally-averaged intensity difference for the cases with and without plasma on the PSP-coated surface.

\section{Conclusions}

The effect of DBD plasma on the film cooling effectiveness of a 30-degree slot was experimentally investigated. The PSP technique was used to measure the film cooling effectiveness. Two input voltages $(6$ and $7 \mathrm{kV})$, two blowing ratios (0.5 and 1.0), and two exposed electrode locations were considered. Based on the measured results, the following conclusions were reached:

(1) Regardless of plasma operation, the film cooling effectiveness of the slot was higher for the 1.0 blowing ratio case than for the 0.5 blowing ratio case.

(2) The case with the higher input voltage $(7 \mathrm{kV})$ showed greater film cooling effectiveness than the case with the lower input voltage $(6 \mathrm{kV})$.

(3) The improvement of the film cooling effectiveness due to the DBD plasma was more significant when the coolant had less momentum, i.e., the case with the lower blowing ratio case or the cases with the exposed electrode located downstream from the slot.

In this study, the enhancement of the film cooling effectiveness using DBD plasma was observed. However, the improvement was not significant. For further improvement in film cooling effectiveness, the DBD plasma-induced flow and the dragging down of the coolant must be increased. A follow-up study aimed at optimizing the configuration of the DBD plasma actuator is currently in progress, and the results will be presented in the near future.

Acknowledgments: This work was supported by a National Research Foundation of Korea (NRF) grant funded by the Korean government (MSIP) (No. NRF-2015R1A2A2A0100236), and the fundamental research of the Defense Acquisition Program Administration and Agency for Defense Development (2015-05-042).

Author Contributions: Jae Su Kwak and Youhwan Shin conceived and designed the experiments; Ye Jee Kim and Gi Mun Kim performed the experiments and analyzed the data; Ye Jee Kim and Jae Su Kwak wrote the paper.

Conflicts of Interest: The authors declare no conflict of interest.

\section{References}

1. Goldstein, R.J. Film cooling. Adv. Heat Transf. 1971, 7, 321-379. [CrossRef]

2. Han, J.C.; Dutta, S.; Ekkad, S.V. Gas Turbine Heat Transfer and Cooling Technology, 2nd ed.; Taylor \& Francis: New York, NY, USA, 2012; p. 5.

3. Bogard, D.G.; Thole, K.A. Gas turbine film cooling. J. Propuls. Power 2006, 22, 249-270. [CrossRef] 
4. Wright, L.M.; Gao, Z.; Yang, H.; Han, J.C. Film cooling effectiveness distribution on a gas turbine blade platform with inclined slot leakage and discrete film hole flows. J. Heat Transf. Trans. ASME 2008, 130. [CrossRef]

5. Papa, M.; Srinivasan, V.; Goldstein, R.J. Film cooling effect of rotor-stator purge flow on endwall heat/mass transfer. J. Turbomach. 2012, 134, 041014. [CrossRef]

6. Oke, R.; Simon, T.; Shih, T.; Zhu, B.; Lin, Y.L.; Chyu, M. Measurements over a film-cooled, contoured endwall with various coolant injection rates. In Proceedings of the ASME Turbo Expo, New Orleans, LA, USA, 4-7 June 2001. ASME Paper 2001-GT-0140.

7. Gao, Z.; Narzary, D.; Han, J.C. Turbine blade platform film cooling with typical stator-rotor purge flow and discrete-hole film cooling. J. Turbomach. 2008, 131, 041004. [CrossRef]

8. Wright, L.M.; Blake, S.A.; Han, J.C. Film cooling effectiveness distributions on a turbine blade cascade platform with stator-rotor purge and discrete film hole flows. J. Turbomach. 2008, 130, 031015. [CrossRef]

9. Corke, T.C.; Post, M.L. Overview of plasma flow control: Concepts, optimization, and applications. In Proceedings of the 43rd AIAA Aerospace Sciences Meeting and Exhibit, Reno, NV, USA, 10-13 January 2005. AIAA Paper 2005-563.

10. Pons, J.; Moreau, E.; Touchard, G. Asymmetric surface dielectric barrier discharge in air at atmospheric pressure: Electrical properties and induced airflow characteristics. J. Phys. D Appl. Phys. 2005, 38, 3635-3642. [CrossRef]

11. Corke, T.C.; Post, M.L.; Orlov, D.M. SDBD plasma enhanced aerodynamic: Concepts, optimization and applications. Prog. Aeosp. Sci. 2007, 43, 193-217. [CrossRef]

12. Thomas, F.O.; Corke, T.C.; Iqbal, M.; Kozlov, A.; Schatzman, D. Optimization of dielectric barrier discharge plasma actuators for active aerodynamics flow control. AIAA J. 2009, 47, 2169-2178. [CrossRef]

13. Moreau, E. Airflow control by non-thermal plasma actuators. J. Phys. D Appl. Phys. 2007, 40, 605-636. [CrossRef]

14. Enloe, C.L.; McLaughlin, T.E.; VanDyken, R.D.; Kachner, K.D. Mechanisms and responses of a single dielectric barrier plasma actuator: Plasma morphology. AIAA J. 2004, 42, 589-594. [CrossRef]

15. Cattafesta, L.N., III; Sheplak, M. Actuators for active flow control. Annu. Rev. Fluid Mech. 2011, 43, $241-272$. [CrossRef]

16. Kogelschatz, U. Dielectric-barrier discharges: Their history, discharge physics, and industrial applications. Plasma Chem. Plasma Process. 2003, 23, 1-46. [CrossRef]

17. Napartovich, A.P. Overview of atmospheric pressure discharges producing nonthermal plasma. Plasma Polym. 2001, 6, 1-14. [CrossRef]

18. Corke, T.C.; Jumper, E.J.; Post, M.L.; Orlov, D. Application of weakly-ionized plasmas as wing flow-control devices. In Proceedings of the 40th AIAA Aerospace Sciences Meeting \& Exhibit, Aerospace Sciences Meetings, Reno, NV, USA, 14-17 January 2002. AIAA Paper 2002-350.

19. He, C.; Corke, T.C.; Patel, M.P. Plasma flaps and slats: An application of weakly ionized plasma actuators. J. Aircr. 2009, 46, 864-873. [CrossRef]

20. Huang, J.; Corke, T.C.; Thomas, F.O. Plasma actuators for separation control of low-pressure turbine blades. AIAA J. 2006, 44, 51-57. [CrossRef]

21. Van Ness, D.K., II; Corke, T.C.; Morris, S.C. Turbine tip clearance flow control using plasma actuators. In Proceedings of the 44th AIAA Aerospace Sciences Meeting and Exhibit, Aerospace Sciences Meetings, Reno, NV, USA, 9-12 January 2006. AIAA Paper 2006-21.

22. Stephens, J.E.; Corke, T.; Morris, S. Blade-mounted single dielectric barrier discharge plasma actuators in turbine cascade. J. Propuls. Power 2011, 27, 692-699. [CrossRef]

23. Benard, N.; Moreau, E. Capabilities of the dielectric barrier discharge plasma actuator for multi-frequency excitations. J. Phys. D Appl. Phys. 2010, 43. [CrossRef]

24. Enloe, C.L.; McLaughlin, T.E.; Van Dyken, R.D.; Kachner, K.D.; Jumper, E.J.; Corke, T.C.; Post, M.; Haddad, O. Mechanisms and Responses of a Single Dielectric Barrier Plasma Actuator: Geometric Effects. AIAA J. 2004, 42, 595-604. [CrossRef]

25. Yu, J.L.; He, L.M.; Zhu, Y.F.; Ding, W.; Wang, Y.Q. Numerical simulation of the effect of plasma aerodynamic actuation on improving film hole cooling performance. Heat Mass Transf. 2013, 49, 897-906. [CrossRef]

26. Dai, S.J.; Xiao, Y.; He, L.M.; Jin, T.; Hou, P.H.; Zhang, Q.; Zhao, Z.C. Computational study of plasma actuator on film cooling performance for different shaped holes. AIP Adv. 2015, 5, 067104. [CrossRef] 
27. Audier, P.; Fenot, M.; Benard, N.; Moreau, E. Flow control of an elongated jet in cross-flow: Film cooling effectiveness enhancement using surface dielectric barrier discharge plasma actuator. Appl. Phys. Lett. 2016, 108, 084103. [CrossRef]

28. Han, J.C.; Rallabandi, A.P. Turbine blade film cooling using PSP technique. Front. Heat Mass Transf. 2001, 1, 013001. [CrossRef]

29. Charbonnier, D.; Ott, P.; Jonsson, M.; Cottier, F.; Kobke, T. Experimental and numerical study of the thermal performance of a film cooled turbine platform. In Proceedings of the ASME Turbo Expo, Orlando, FL, USA, 8-12 June 2009. GT2009-60306.

30. Kline, S.J. The purposes of uncertainty analysis. J. Fluids Eng.-Trans. ASME 1985, 107, 153-160. [CrossRef]

31. Abernethy, R.B.; Benedict, R.P.; Dowdell, R.B. ASME measurement uncertainty. J. Fluids Eng. Trans. ASME 1985, 107, 161-164. [CrossRef]

32. Benard, N.; Moreau, E. Electrical and mechanical characteristics of surface AC dielectric barrier discharge plasma actuators applied to airflow control. Exp. Fluids 2014, 55, 1846. [CrossRef]

(C) 2017 by the authors. Licensee MDPI, Basel, Switzerland. This article is an open access article distributed under the terms and conditions of the Creative Commons Attribution (CC BY) license (http:/ / creativecommons.org/licenses/by/4.0/). 